\title{
Acordes e melodias na "cidade partida": o tema da segregação sócioespacial cantado por alguns sambistas cariocas
}

\author{
Alexandre Moura Pizotti
}

Mestre em Geografia pela Universidade do Estado do Rio de Janeiro (UERJ) e professor da Rede Particular de Ensino da Cidade do Rio de Janeiro.E-mail:ampizotti@yahoo.com.br

Recebido em 04/2012. Aceito para publicação em 12/2012.

Versão online publicada em 01/02/2013 (http://seer.ufrgs.br/paraonde)

\begin{abstract}
Resumo - Discutir como o tema da segregação espacial na cidade do Rio de Janeiro é experienciado por alguns compositores do Morro da Mangueira ou simpatizantes desta comunidade, a partir da análise de algumas letras de sambas enredo, quadra ou terreiro é o objetivo central desta comunicação. Para isso, recorreremos aos aportes teóricos e metodológicos da corrente denominada de Geografia Humanística, em especial as noções de espaço e lugar. Como outras pesquisas produzidas dentro da corrente humanística, este esforço está assentado na subjetividade, na intuição, nos sentimentos, na experiência, no simbolismo e na contingência, privilegiando o singular e não o particular ou o universal, e ao invés da explicação, tem na compreensão a base de inteligibilidade do mundo real. A alusão a um mundo "mítico", "sagrado", criado ao longo dos anos pela rica produção cultural do Morro da Mangueira, além do prestígio de sua agremiação carnavalesca, dentro da inoperância e negligência do poder público, mas no compasso do surdo e no rufar de seus tambores, forjou uma imagem, carregada de simbolismos, que contribui para a diminuição de representações estigmatizadas e preconceituosas de seus moradores, inserindo-os na "cidade formal", ou seja, derrubando os "muros do resguardo" entre a favela e o asfalto, se não na paisagem urbana, no imaginário coletivo.

Palavras-chave: Geografia Humanística. Segregação Sócio-espacial. Rio de Janeiro. Samba. Favela da Mangueira.
\end{abstract}

\section{Introdução}

0 presente artigo busca discutir como o tema da segregação espacial na cidade do Rio de Janeiro é experienciado por alguns compositores do Morro da Mangueira ou simpatizantes desta comunidade, a partir da análise de algumas letras de sambas enredo, quadra ou terreiro. Para isso, recorreremos aos aportes teóricos e metodológicos da corrente denominada de Geografia Humanística, em especial as noções de espaço e lugar. Nos anais da perspectiva humanística, estes conceitos apresentam uma significativa diferenciação a começar pela noção de espaço, visto como qualquer parte da superfície terrestre desconhecido, inseguro, aberto, temido ou rejeitado, em suma, pouco experienciado pelos indivíduos. O lugar, ao contrário, seria aconchegante, seguro, conhecido e cheio de significados. Recortado emocionalmente emerge das experiências, ao longo da vida, dos indivíduos e de suas práticas cotidianas como ir ao trabalho, às compras ou à escola, assumindo assim uma conotação de lugar vivido, muito íntimo e particular (TUAN, 1983, 1998). Marcada pela crítica às geografias de cunho lógico-positivista, a geografia humanista é calcada nas filosofias do significado, como a fenomenologia e o existencialismo. A fenomenologia é a filosofia presente em um maior número de estudos humanísticos em geografia. 0 termo foi criado, em 1764, por J. H. Lambert e, a partir daí, recebeu significações diferentes, notadamente aquelas dadas pelos alemães Immanuel Kant (1724 - 1804) e Georg Wilhelm Friedrich Hegel (1770 - 1831) e, sobretudo, por Edmund Husserl (1859 -1938) (GOMES, 2003). Segundo Mattos: 
Cabe à fenomenologia o pioneirismo na adoção de dimensões como os laços de vizinhança, a preferência por determinados pontos de uma cidade, a afeição a um lugar (topofilia), bem como o ódio a certos espaços (topofobia), o medo a outros (agorafobia), a afeição a ambientes fechados (claustrofilia), a morte dos lugares (topocídio), a restauração de outros (toporeabilitação), afora a topoindiferença, (TUAN, 1980), bem como as experiências cotidianas na abordagem geográfica.

A hermenêutica, outra filosofia do significado utilizada pelos geógrafos humanísticos, "tem sua origem na Antiguidade, inspirada na mitologia grega de Hermes, deus da comunicação, encarregado de trazer as mensagens do Olimpo" (GOMES, 2003, p.112). A constituição de um método hermenêutico moderno começa com o alemão Johann Gottfried Herder (1744 - 1803), estabelecendo uma inteligibilidade circunscrita às condições espaço-temporais, sendo seguido por outros filósofos como Wilhem Dilthey (1833 - 1911). Também conhecida como filosofia interpretativa, a hermenêutica busca, em linhas gerais, compreender e interpretar as contradições e ambivalências da consciência dos indivíduos e/ou grupos sociais com relação ao seu meio ambiente natural ou socialmente produzido. A compreensão segundo esta corrente filosófica é então promovida ao nível de instrumento epistemológico passando a ser um novo pólo da produção do saber, num primeiro momento originário do pensamento artístico e religioso, manifestando-se mais tarde nas ciências, principalmente nas ciências sociais. Compreender é alcançar uma significação, explicar o obscuro, revelar uma essência. Os fatos são expressivos por serem portadores de um sentido. Ainda segundo Gomes, citando Dilthey:

Compreender seria também o ato de encontrar nos fatos a intenção dos outros, de se colocar em comunicação com eles. A compreensão seria sempre sintética, cujo objeto não pode ser decomposto em elementos mais simples, e deve ser guiada pela intuição e pelo sentimento, sem descartar a subjetividade, de tal maneira que a compreensão possa alcançar imediatamente as totalidades sem recorrer à razão (2003, p. 114).

Diante do exposto, as pesquisas produzidas dentro da corrente humanística estão assentadas na subjetividade, na intuição, nos sentimentos, na experiência, no simbolismo e na contingência, privilegiando o singular e não o particular ou o univer- sal, e ao invés da explicação, tem na compreensão a base de inteligibilidade do mundo real (MELLO, 1991). Antes da proposição de aplicação destes pressupostos teóricos na análise e interpretação de algumas letras de sambas, consideramos oportuno uma breve revisão dos processos e agentes envolvidos na evolução e consolidação da segregação sócio-espacial na paisagem da cidade do Rio de Janeiro.

\section{A "cidade partida"}

A oposição entre o "meu mundo" e o "mundo dos outros" é um valor presente nas sociedades humanas há bastante tempo. Nas antigas cidades medievais, suas muralhas e portões demarcavam o horizonte de ações de seus habitantes, opondo à segurança intramuros o acaso e o desconhecido de "lá fora". Com o adensamento das cidades e a expansão de seus limites, a cidade, ela mesma, passa a ser um perímetro estranho a novos moradores vindos de outras regiões ou visitantes ocasionais. Atualmente, o homem moderno, morador das grandes metrópoles, constrói física ou simbolicamente muralhas e portões que o protegem do caos, males, perigos ou incertezas da vida urbana. Por exemplo, os indivíduos e grupos de alta renda podem se auto-segregar em condomínios luxuosos ou bairros distantes da área central das cidades, estas geralmente apinhadas de pessoas, automóveis, barulho e poluição. Para outros setores menos favorecidos da sociedade, por outro lado, sua exclusão em relação à "cidade formal" é resultado, na maioria das vezes, de processos que estão além de seus anseios e desejos. Para Mello (1991, p.163) "protegidos em seu mundo por muralhas e portões ou excluídos de outros mundos, o homem urbano vive diversos tipos de segregação espacial, geopolítica e territorialidades". Talvez uma das expressões atuais mais singulares da segregação espacial no tecido urbano carioca é a materialização na paisagem da oposição entre a "cidade formal" e as favelas, pelo fato de muitas destas comunidades estarem localizadas em áreas nobres da cidade, voltadas inicialmente a abrigar uma população de alto status social.

O fenômeno em questão, ainda não explicitamente associado à pobreza, e com pouca expressão espacial, já poderia ser percebido nas primeiras décadas após a fundação do Rio de Janeiro, pela ocupação dos morros da área central da cidade por instituições que simbolizavam o poder, como as igrejas, ou nas chácaras aristocráticas que se autosegregavam de maneira rarefeita ocupando as encostas de algumas colinas na/ou próximas a área 
central da cidade em busca de amenidades e salubridade, uma vez que nos primeiros séculos do período colonial, os diferentes estratos sociais habitavam em residências localizadas em ruas e ruelas comuns, devido à existência de poucas áreas edificáveis em um sítio urbano entremeado por brejos, mangues, pântanos e lagoas, sendo apenas a fachada dos casarios o indicativo da posição social de seus proprietários.

Com a execução de grandes obras já a partir do século XVII, como a dragagem de brejos e pântanos, o aterramento de lagoas, a ampliação e criação de novos caminhos e estradas e, principalmente, com a expansão dos meios de transportes entre os séculos XIX e XX, somado ao aumento demográfico, marcado pela precária inserção de boa parte desta população ao circuito econômico citadino, a forma urbana da cidade se tornou cada vez mais complexa e a ocupação de seu tecido passa a ser mais nitidamente marcada pelo uso segregado entre as classes sociais. Ademais, é também a partir do início do século XX que o poder público, influenciado pelas ideias positivistas de ordem e progresso e buscando extinguir da paisagem a cidade colonial, passa a controlar e induzir a expansão da forma urbana por meio de planos urbanísticos, expulsando para os distantes subúrbios ou para as encostas dos morros aquela população considerada "indesejada", como lavadeiras, biscateiros, ambulantes, estivadores, entre outros, "oficializando" a fragmentação do espaço carioca como um dos traços de sua paisagem.

Nestes morros, alguns deles localizados próximos ou em bairros ocupados pelas classes sociais mais favorecidas, um grande número de indivíduos, no início majoritariamente originários de outras áreas da cidade e mais tarde de fora dela, de maneira criativa e a princípio provisória, encontraram uma solução no morar próximo aos seus locais de trabalho, diminuindo sensivelmente seus custos de transporte. Em muitos casos, para estes indivíduos, tais ocupações se constituíam na prestação de serviços diversos demandados pela população destes bairros limítrofes ou para a logística da cidade, contribuindo para o surgimento e crescimento de várias favelas (ABREU, 1997). A convivência destas comunidades a partir da sua efetiva inserção no tecido urbano com a chamada "cidade formal", no campo das representações, foi pontuada em certos períodos por discursos humanitários que enfatizavam suas carências de infra-estrutura. Entretanto, predominaram aqueles discursos que alimentavam preconceitos, estigmas, medos e incertezas, erguendo muros simbólicos concretamente experienciados nas relações interpessoais cotidianas. Estes muros se encontram ainda hoje profundamente enraizados em parte significativa do imaginário coletivo dos moradores dos chamados bairros formais, principalmente com o aumento da violência urbana a partir dos anos 1980. Ademais, termos como "excluídos" ou "cidade partida", tão popularizados pela imprensa carioca e até mesmo nacional nos dias de hoje, errôneos ou no mínimo simplistas, uma vez que o "asfalto" e o "morro" são duas dimensões da mesma cidade, acabam por contribuir ainda mais para a propagação de representações estigmatizadas da pobreza.

Todavia, tais muros podem ser superados, principalmente por meio de manifestações culturais como a música, meio com grande potencial de penetração em diversas camadas da sociedade e quase onipresente na vida cotidiana. Compreender como alguns sambas traduziram nas suas letras os sentimentos e experiências de seus compositores com relação a esta dicotomia sócio-espacial marcante da paisagem carioca, contribuindo para a superação destes muros, particularmente aqueles que separam o Morro da Mangueira de outras áreas da cidade, é o empreendimento deste artigo. Como a literatura musicada da e sobre a Mangueira é bastante rica e extensa, buscamos selecionar aquelas canções que entendemos terem em seus versos as dimensões espaciais e simbólicas que pretendemos analisar e destacar, tendo em vista também as limitações do trabalho em tela. Neste contexto, nos debruçaremos nas letras de cinco canções selecionadas de nosso próprio acervo, entre os anos de 1930 e 2000. Como um relato do mundo vivido a respeito destes muros e portões, a apreciação destas canções ao longo deste período temporal pode também contribuir para descortinar as permanências ou mudanças das experiências de seus compositores com relação ao tema em tela. Para fins de exposição, reproduziremos apenas um trecho ou parte de uma determinada composição. Buscando compreender os insights ligados às motivações para a produção das composições e os contextos em que estas ocorreram, assim como sobre os significados e os efeitos pretendidos, é considerado um breve histórico relativo ao (s) compositor (es) com informações a respeito de sua classe social, lugar de origem e residência, instrução, entre outros, procedimento proposto por Mello (1991). Acreditamos que o uso destas informações adicionais nos ajudam a penetrar nos significados buscados pelos autores, assim como melhor compreender as idéias contidas nas composições dos mesmos, plenas de sentimentos e evocações (KONG, 2009). 


\section{"Portões" e "muros" da exclusão}

Desde o início do século XX, o morro da Mangueira (antes denominado de Telégrafos pelo fato desta elevação ser o ponto mais alto e próximo ao Palácio da Quinta da Boa Vista, e utilizado para a instalação da rede do sistema telegráfico implantado pela família real no Brasil), tornou-se o destino para levas de pessoas de diferentes origens sociais. Teria surgido em 1900, ligado a um conjunto de operários que trabalhavam na Cerâmica Brasileira, estabelecimento que se localizava na Avenida Visconde de Niterói, logradouro que margeia a base do morro. Seus primeiros barracos, construídos ilegalmente por alguns "imigrantes portugueses inovadores, tiveram importante papel no loteamento 'oficioso' da colina nesta primeira fase, na parte da encosta voltada para a Quinta da Boa Vista" (LESSA, 2000, p.307). Alguns anos mais tarde, a encosta receberia uma nova leva de moradores, sendo estes militares retirados durante a administração Serzedelo Corrêa, devido às obras de remodelação da antiga Quinta da Boa Vista, durante o ano de 1908. No decorrer das décadas seguintes, sua população vai se adensando com o contínuo fluxo de pessoas oriundas de outras partes da cidade ou regiões do país, notadamente da Região Nordeste.

O samba "subiu" o morro da Mangueira por intermédio de um jongueiro e sambista que morava em Madureira, Mano Elói (FERNANDES, 2001), e encontrou nesta colina um de seus grandes representantes, Angenor de Oliveira, ou Cartola, considerado por diversos músicos e críticos como um dos maiores sambistas da história da música brasileira. Um dos fundadores da verde e rosa Grêmio Recreativo Escola de Samba Estação Primeira de Mangueira, em 1928, Cartola esteve à frente de desfiles memoráveis da agremiação, que se sagraria campeã do carnaval carioca por 17 vezes. Além de Cartola, as encostas, becos e ruelas do Morro da Mangueira foram testemunhas do surgimento de outros grandes compositores e intérpretes como Carlos Cachaça, Nelson Sargento, Jamelão, Hélio Turco, Sinhô, Nelson Cavaquinho e muitos outros. Na cadência do samba emanado da colina por seus compositores e simpatizantes e no ritmo de seus desfilantes, esta modalidade rítmica e sua agremiação carnavalesca, proporcionaram para a comunidade ao longo dos anos notoriedade no imaginário carioca, nacional e internacional, não deixando que outras mazelas sociais, comuns a muitas comunidades na cidade, diminuíssem o brilho e a importância cultural do Morro da Mangueira para os cariocas.

Abrigando atualmente um grande número de moradores, a comunidade mangueirense apresenta um espaço físico desordenado do ponto de vista jurídico, que limita a sua incorporação à cidade. Como outras favelas, seus moradores carregam as representações e estigmas que, no campo simbólico e para além dos limites físicos, erguem "muros" e "barreiras" que os excluem das esferas política, civil e social da cidade. Entretanto, no caso particular da Mangueira, de notável produção cultural, o morro e seus habitantes, marginalizados no interior do espaço urbano passam, através do samba, como forma de narrativa do lugar vivido, a serem reverenciados e valorizados, e a favela, transformada em um grande eldorado. Eis a seguir um pequeno elenco de canções que abordam a temática em questão.

\section{Eu quero Nota (1930) Arthurzinho}

"Eu quero é nota / Carinho e sossego / Para viver descansado / Cheio de alegria, meu bem / Com uma cabrocha ao meu lado / Eu queria ter dinheiro que fosse grande porção / Eu comprova um automóvel / Ia morar lá no Leblon / Sou um triste operário / Não posso bancar barão / Vou morar lá em Mangueira / Num modesto barracão /Eu quero é nota / Todo mundo acha graça / De um pobre vagabundo / Se a sorte fosse igual / Ninguém ria neste mundo / Eu desço de madrugada / Enganando a moçada /Que vou trabalhar /Porém quando a fábrica apita / Pego na minha marmita / Vou me alimentar".

No carnaval de 1930, a então recém fundada Estação Primeira de Mangueira levava para o desfile o samba-enredo de Arthurzinho "Eu quero nota". Com pouca repercussão na impressa da época (FERNANDES, 2001), a escola já denunciava a desigualdade social e espacial da geografia carioca que marcaria a forma urbana da cidade nas décadas seguintes. Na canção, um proletário e favelado pede, além de carinho e sossego, "nota", para viver descansado. Consciente de sua situação social e dos muros que excluem e segregam, o trabalhador afirma, "...eu queria ter dinheiro que fosse grande porção / eu comprava um automóvel / ia morar lá no Leblon / Sou um triste operário / não posso bancar barão / vou morar lá em Mangueira / num modesto barracão..." em clara alusão a dois símbolos de status e visibilidade social: o automóvel e o sofisticado bairro do Leblon, planejado a partir do início do século vinte para abrigar cidadãos de alto poder aquisitivo por meio da iniciativa imobiliária e do poder público e hoje um dos metros quadra- 
dos mais caros da cidade. Aponta também para o preconceito que a população moradora dos morros sofre e culpa como responsável por este fato o destino infeliz: "...todo mundo acha graça / de um pobre vagabundo / se a sorte fosse igual / ninguém ria neste mundo...". Mesmo assim, o nosso operário dribla com criatividade as dificuldades encontradas pelo seu caminho em busca de prazeres simples, dentro de sua vida repleta de lutas e, ao mesmo tempo, pratica escapismo: “...eu desço de madrugada / enganando a moçada / que vou trabalhar / porém quando a fábrica apita / pego na minha marmita / vou me alimentar".

\section{Carnaval de todos os tempos (1960) Hélio Turco, Cícero e Pelado}

"Samba melodia divina / Tu és mais empolgante / Quando vens da colina / Samba original és verdadeiro / Orgulho do folclore brasileiro / 0 teu linear de vitórias / Foi na Praça Onze de outrora / Das lindas fantasias / Que cenário multicor / Das velhas batucadas / E o saudoso Sinhô / Oh! Que reinado de orgia / Onde o samba imperava / Matizando alegrias / Rei momo e as escolas de samba / Deram mais esplendor /Ao nosso carnaval / E o samba fascinante / Ingressa no Municipal / Sua epopéia triunfante / Atingiu terras bem distantes / Não encontrando fronteiras / $\mathrm{O}$ samba conquistou / Platéias estrangeiras".

O compositor Hélio Rodrigues Neves (1935) ou Hélio Turco, natural do Grajaú, bairro da zona norte carioca, mudou-se para a Mangueira aos seis meses de idade. Seu nome artístico foi herdado de seu tio Jorge Turco, dono de um armarinho, que mais tarde ficou aos cuidados de seu sobrinho. Todos pensavam que fosse filho de Jorge Turco, daí o apelido. Iniciou sua carreira de compositor por acaso na Ala dos Compositores da Escola de Samba do morro de Mangueira em 1957 (que então passava por uma crise e precisava formar uma nova diretoria) quando, por falta de quórum, foi indicado por um amigo enquanto assistia uma reunião, embora até então não tivesse composto. Sua primeira composição apareceu em 1958, o samba "Decaída". (INSTITUTO CULTURAL CRAVO ALBIN, 2012).

Cícero dos Santos (1923 - 1994) foi estivador do cais do porto do Rio de Janeiro. Foi eleito presidente da Estação Primeira de Mangueira em 1956 e anos mais tarde, presidiu a Ala dos Compositores da escola. Foi parceiro do compositor Pelado em vários sambas. Jorge Alves de Oliveira, o Pelado (1921 - 1980) morou em Mangueira toda a sua vida. 0 pai, José Alves de Oliveira, também conhecido como Zé das Pastorinhas, foi um dos fundadores da Escola de Samba Unidos da Mangueira, escola que rivalizava com a Estação Primeira de Mangueira nos primeiros concursos carnavalescos. (INSTITUTO CULTURAL CRAVO ALBIN, 2012).

No samba-enredo "Carnaval de todos os tempos", seus compositores nos convidam a rever (ou para os mais desavisados, ter contato pela primeira vez) alguns capítulos que marcaram a evolução geográfica e histórica do samba, em particular aquele dos compositores da Mangueira "...samba melodia divina / tu és mais empolgante / quando vens da colina...." O samba propagado pelas recém fundadas escolas de samba, entre elas a Estação Primeira de Mangueira, considerado no início de sua evolução na cena cultural carioca um ritmo marginal, por meio de seus compositores e desfiles, envereda pela seguinte senda: "...o teu linear de vitórias / foi na Praça Onze de outrora / das lindas fantasias / que cenário multicor / das velhas batucadas / e o saudoso Sinhô.... Nestes compassos mapeia o "berço do samba" e dos desfiles das escolas, mostra que tal manifestação passou a atrair cada vez mais adeptos e cita o lendário e excelente compositor Sinhô que, nos domínios da Praça Onze e da Cidade Nova, intitulava-se o "Rei do Samba". Seus desfiles, exaltação máxima deste ritmo musical, acompanhando esta popularização, tornam-se mais grandiosos e luxuosos como podem ser lidos nos versos "...Rei Momo e as escolas de samba / deram mais esplendor / ao nosso carnaval...". Mais adiante, nos lembra os compositores, já culturalmente reconhecido e integrado no imaginário carioca, esta grande festa chega a outros palcos tradicionais da cidade e platéias mais exigentes "...e o samba fascinante / ingressa no Municipal / sua epopéia triunfante...", referência ao reduto das artes eruditas que no período momesco se constituía, igualmente, em palco para a folia.

Os primeiros versos de "Carnaval de todos os tempos", impregnados de orgulho, traduzem emblematicamente as querelas e os desdobramentos entre a favela e o poder público em seu tempo, marcado por um discurso oficial que passa a encarar estas comunidades como espaços caóticos que deveriam ser removidos. Apoiada em motivações variadas como a retirada de populações que "manchavam" o status sofisticado de bairros da zona sul da cidade, criação de áreas edificáveis para o capital imobiliário ou a abertura de ruas e alargamento de avenidas, a remoção desarticula laços comunitários e topofílicos enraizados nos lugares, criando para famílias inteiras um futuro de incertezas e angústias em um novo espaço. Contrários a tal 
intervenção em seu mundo vivido, os anos 1960 testemunham também uma série de iniciativas organizacionais entre as favelas cariocas que clamavam pela manutenção destes laços topofílicos. Com a vitória da emoção em relação à razão, muitas comunidades, entre elas a Mangueira, marcada pela forte personalidade urbana conferida pelo samba emanado de sua colina e por sua agremiação carnavalesca, consolida-se no espaço urbano afastando o perigo da remoção. Logo a seguir, a paisagem da colina sofre uma metamorfose: as antigas habitações construídas com materiais como zinco e madeira passam a ser substituídas pela alvenaria. Diante do exposto, ao longo deste rico desenrolar de lutas, inovações, poesias e afirmações, concomitantemente à crescente adesão de simpatizantes para além de suas cercanias, o samba mangueirense se torna um dos símbolos da auto-estima carioca, influindo de forma substancial na permanência de seus moradores no morro, mundo vivido dos sambistas e território sacralizado por sua agremiação carnavalesca, chamando a atenção do poder público e de setores da sociedade para os sentimentos que unem os indivíduos aos seus lugares. Além disso, a reconhecida produção cultural do Morro da Mangueira, "orgulho do folclore brasileiro", contribuiu também para a redução dos estigmas e ampliação dos horizontes de relações entre a comunidade e outros redutos da "cidade formal" e até mesmo paragens mais distantes "...não encontrando fronteiras/ o samba conquistou / plateias estrangeiras...".

\section{Cem anos de liberdade. Realidade ou ilusão (1988)}

\section{Hélio Turco, Jurandir e Alvinho}

“... Pergunte ao criador/Pergunte ao criador/ Quem pintou esta aquarela/ Livre do açoite e da senzala/Preso na miséria da favela (....)".

Até o ano de 1988, centenário da Abolição da escravidão no Brasil, a melhoria estética e de qualidade dos antigos barracões de madeira para casas de alvenaria nos morros cariocas não se traduziu em mobilidade social para seus moradores. Incorporadas ao cenário urbano e enfrentando problemas como falta de água, luz e esgoto, que ainda persistiam a despeito da política paternalista e pontual do poder público, as favelas cada vez mais se tornavam o lugar do pobre, principalmente dos negros. A expansão e criação de favelas em diversas áreas mostrava que a tentativa de controlar a forma urbana da cidade, separando no espaço ricos e pobres, através de sucessivas reformas e interven- ções do poder público, tinha fracassado. Na obra "Paisagens do Medo", Tuan discorre sobre a criação de paisagens do medo pelos homens, oferecendo instrumentos de compreensão para o fenômeno da segregação espacial. Segundo ele:

\begin{abstract}
Falando genericamente, cada fronteira criada pelo homem na superfície da Terra - cerca do jardim, muro da cidade, ou "barreira do radar" - é uma tentativa de manter afastadas as forças inimigas. Limites existem em todos os lugares porque as ameaças são onipresentes: o cão do vizinho, criança com sapatos lamacentos, estranhos, o louco, exércitos estrangeiros, doenças, lobos, vento e chuva (2006, p.6).
\end{abstract}

Caberia também acrescentar, no caso em tela, o pobre, o negro e o favelado. Atento a este fato, o "samba-denúncia" mangueirense "Cem anos de liberdade: realidade ou ilusão?", composto por Hélio Turco, Jurandir e Alvinho no carnaval de 1988, sublinha este estado de servidão "mascarada" vivenciado pela população das favelas cariocas. Desnorteado na tentativa de buscar explicações para este fenômeno social criado no mundo dos homens, os autores recorrem a ajuda divina, justa, onipresente, “...pergunte ao Criador quem pintou esta aquarela...". Na visão dos sambistas, retratando um momento da favela, surge uma aquarela em preto e branco, "...livre do açoite da senzala, preso na miséria da favela...". Observa-se assim que, no campo tangível, material, a segregação entre o morro e o asfalto se mostrava muito pequena e tênue, no campo imaginário e simbólico, "muralhas", "muros" e portões criados pela mente humana tratavam de excluir outros homens em seus mundos. 0 "bacana" do asfalto, e seu revés, o "vagabundo" ou "malandro" da favela, cada um vivendo sua realidade, pois "além das muralhas, o mundo é proibido, da 'perdição', caótico e distante da fraternidade que pode ser sentida no mundo vivido" (MELLO, 1991, p.151), sentimento compartilhado pelas comunidades faveladas e também pelos mangueirenses.

\section{Piano na Mangueira (1991) \\ Chico Buarque e Antônio Carlos Jobim}

"Mangueira / Estou aqui na plataforma / Da estação primeira / 0 morro veio me chamar / De terno branco / E chapéu de palha / Vou me apresentar / À minha nova parceira (majestosa) / Mandei subir o piano / Pra Mangueira / A minha música não é de / Levantar poeira / Mas pode entrar no 
barracão / Onde a cabrocha pendura a saia / No amanhecer da quarta-feira/Mangueira, Estação Primeira de Mangueira".

Um dos nomes mais representativos da música popular nacional, o compositor e maestro Antônio Carlos Brasileiro de Almeida Jobim (1927 -1994) nasceu na cidade do Rio de Janeiro, no bairro da Tijuca, mudando-se para Ipanema em 1931. Lá viveu com os avós maternos, Mimi e Azor, os pais e sua única irmã, Helena Jobim. Iniciou seus estudos de música em 1941. Além dos estudos musicais, cursou também a Faculdade de Arquitetura. No início de sua carreira, trabalhou como pianista em diversas casas noturnas cariocas, como Sacha's, Monte Carlo e Casablanca. Em 1956, foi apresentado a Vinicius de Moraes, que viria a se tornar seu parceiro mais importante. Uma de suas músicas, "Garota de Ipanema", atingiu o topo do hit parade americano, tendo sido também regravada por diversos intérpretes nacionais e internacionais. Com sólida produção musical e reconhecido internacionalmente, faleceu no dia 8 de dezembro de 1994, aos 67 anos de idade em Nova York. (INSTITUTO CULTURAL CRAVO ALBIN, 2012).

Em "Piano na Mangueira", em parceria com Chico Buarque, o abismo social e espacial que separam os dois compositores, moradores de bairros nobres da zona sul carioca e o Morro de Mangueira é simbolicamente superado. Jobim, merecidamente havia sido homenageado com um enredo em sua honra que o motivou a escrever uma música conectando estes "dois mundos cariocas". Nos versos da canção, Tom Jobim e Chico Buarque desembarcam na estação ferroviária da Central do Brasil e pedem, cordialmente, para adentrar no rico universo cultural mangueirense "...Mangueira/ estou aqui na plataforma/ da estação primeira/ o morro veio me chamar..." A formalidade e solenidade do evento pede, inclusive, indumentária apropriada “...de terno branco/ e chapéu de palha/ vou me apresentar/ à minha nova parceira (majestosa)..." Os compositores, de reconhecido talento musical e prestígio internacional, se rendem e reverenciam a criatividade e a genialidade dos sambistas do morro “...mandei subir o piano/ pra Mangueira/ a minha música não é de/ levantar poeira/ mas pode entrar no barracão...", confluindo a batida sofisticada do samba da zona sul com o rufar dos tambores da verde rosa de Cartola, Nélson Cavaquinho, Dona Neuma, Dona Zica, Tom Jobim e "Chico Buarque da Mangueira".

\section{Dom Obá II Rei dos esfarrapados, príncipe do povo (2000)}

\section{Marcelo D'Aguiã, Bizuca, Gilson Bernini e Valter Veneno}

“No Rio de lá / Luxo e riqueza / No Rio de cá / Lixo e pobreza / Frequentei o palácio imperial / Critiquei a elite no jornal / Desejei liberdade / 500 anos Brasil / E a raça negra não viu / O clarão da igualdade / Fazer o negro respirar felicidade / Sonho ou realidade?/ Uma dádiva do céu (do céu, do céu) / Vi no morro da Mangueira / Sambar de porta-bandeira / A Princesa Isabel".

Com "Dom Obá II Rei dos esfarrapados, príncipe do povo", o quarteto de compositores Marcelo D'Aguiã, Bizuca, Gilson Bernini e Valter Veneno conduzem mais uma vez para o desfile do carnaval carioca um samba-enredo que discute a segregação sócio-espacial denunciada pelos autores já nos primeiros versos da composição "...no Rio de lá/ luxo e riqueza / no Rio de cá/ lixo e pobreza..... Em meio aos quinhentos anos de descobrimento do Brasil, os sambistas discutem também as muralhas levantadas pelo racismo que ainda excluem e dificultam a ascensão social da população negra em nossa sociedade "...desejei liberdade/ 500 anos Brasil/ e a raça negra não viu/ o clarão da igualdade/ fazer o negro respirar felicidade..." O samba assinado por Marcelo D'Aguiã, Bizuca, Gilson Bernini e Valter Veneno, vale repetir, destaca a importância de personalidades negras pouco lembradas pela história oficial celebrando a memória de Cândido da Fonseca Galvão (1845 - 1890), o Dom Obá II D`África, ou simplesmente Dom Obá. Filho de africanos forros e de ascendência nobre, Dom Obá lutou na Guerra do Paraguai e devido a sua grande bravura foi condecorado como oficial honorário do exército brasileiro. Depois da Guerra fixou-se no Rio de Janeiro, tornando-se uma figura folclórica e um tanto quanto caricata da sociedade carioca, sendo até reverenciado como um príncipe real por vários afro-brasileiros. Foi amigo pessoal do imperador D. Pedro II e seu importante interlocutor na "Pequena África" da Praça Onze. Quando da Proclamação da República, Dom Obá organizou um movimento com os negros da Praça Onze que correram para apoiar a Monarquia em detrimento da positivista ordem que se impunha em solo brasileiro. Seu nome hoje está imortalizado em um logradouro na Praça da Bandeira, bairro próximo a área central da cidade (LESSA, 2000).

Mais adiante, em meio a devaneios, os autores vislumbram a demolição dos "muros" que excluem toda uma população negra (grande parte dela residente em outros morros cariocas) da comunidade da Mangueira, bem como a alegria e o 
congraçamento emanados pela sua agremiação carnavalesca "...sonho ou realidade?/ uma dádiva do céu (do céu, do céu) / vi no morro da Mangueira/ sambar de porta-bandeira / a Princesa Isabel...", mesclando em sonho a presença da Redentora sambando garbosamente com o pavilhão da escola verde e rosa.

\section{Considerações Finais}

A partir da exposição das canções nas páginas anteriores e buscando trilhar o caminho da lógica da descoberta, procuramos a cada verso traduzir o sentimento e o entendimento dos compositores e simpatizantes do Morro Mangueira a respeito da segregação sócio-espacial desta comunidade na urbe carioca. Neste contexto, a pesquisa se apoiou nos fundamentos teóricos e metodológicos da Geografia Humanística, baseados na fenomenologia e hermenêutica, aportes que contribuem para a elucidação do rico mundo vivido mangueirense.

No início da ocupação de suas encostas, o Morro da Mangueira, assim como outras favelas cariocas que davam seus primeiros passos, eram considerados como espaços indiferentes, rejeitados, caóticos ou semelhantes à roça (LESSA, 2000,) no imaginário dos outsiders cariocas. Tais representações nos discursos oficiais se traduziram na urgente necessidade de suas remoções da paisagem carioca, pois não se adequavam aos projetos positivistas para a forma urbana da cidade. Entretanto, a partir de 1920 com a progressiva valorização das manifestações da cultura popular como o samba, tem início a conversão da colina em um dos símbolos da cidade por intermédio deste ritmo musical. O samba, oriundo do "asfalto", na Pequena África da Praça Onze, já em fins do século XIX (LESSA, 2000) como um produto cultural voltado inicialmente ao autoconsumo das populações pobres e negras, "subiu" para alguns morros cariocas como o Morro da Mangueira, onde encontrou um dos seus poetas supremos, Angenor de Oliveira, o Cartola. Nesta colina, com a fundação em 1928 da verde e rosa Grêmio Recreativo Escola de Samba Estação Primeira de Mangueira, o samba desempenhou uma função dual. Foi fundamental para a consolidação dos laços comunitários e de solidariedade entre seus moradores, contribuindo para a criação de laços topofílicos, visto que sua Associação de Moradores só foi criada em 1968. Além disso, o samba emanado da colina por seus compositores e simpatizantes, converteu tal colina em um lugar / lar de grande significado na alma do carioca e do povo brasileiro consagrado por cada visita ilustre (Pelé, Hortência, Bill Clinton, Morgan Freemam e outros) ou a cada prêmio recebido (Certificado de Excelência concedido pela Casa Branca ou pela BBC de Londres).

Em suma, pretendemos com este trabalho compreender, de maneira introdutória, como o samba produzido pelos moradores ou simpatizantes do Morro da Mangueira contribuiu para a superação, e até mesmo extinção no campo simbólico, dos "muros" e "portões" que segregariam a comunidade da chamada "cidade formal", não deixando que algumas mazelas sociais, comuns a estas comunidades, diminuíssem o brilho, a importância cultural e a notoriedade no imaginário carioca, nacional e internacional da colina, metamorfoseando seus moradores, parcela da população da "cidade partida" estigmatizada aos olhos e mentes do "asfalto", em cidadãos de uma cidade maravilhosa verdadeiramente mais humana.

\section{Referências}

ABREU, Maurício de Almeida. Evolução Urbana do Rio de janeiro. $3^{\circ}$ ed. Rio de Janeiro: Instituto Pereira Passos (IPP), 1997.

FERNANDES, Nelson da Nobrega. Escolas de samba: sujeitos celebrantes e objetos celebrados: Rio de Janeiro, 1928-1949. Rio de Janeiro: Coleção Memória Carioca, v. 3, Arquivo Geral da Cidade do Rio de Janeiro, 2001.

GOMES, Paulo Cesar da Costa. Geografia e Modernidade. $4^{\circ}$ ed. Rio de Janeiro: Bertrand Brasil, 2003.

INSTITUTO CULTURAL CRAVO ALBIN. Dicionário Cravo Albin da Música Popular Brasileira. Rio de Janeiro, RJ, [ 200 - 0 . Dis ponível e m: $<$ http://www.dicionariompb.com.br>. Acesso em 03 jan. 2012.

KONG, Lily. Música Popular nas análises Geográficas. In: Cinema, Música e Espaço. ROSENDAHL, Zeny; CORRÊA, Roberto Lobato. (Orgs). Rio de Janeiro: EdUERJ, v.16, 2009. p. 129-175.

LESSA, Carlos. 0 Rio de todos os Brasis. $3^{\circ}$ ed. Rio de Janeiro: Editora Record, 2000.

MATTOS, Rogério Botelho. O Mundo Vivido por uma Comunidade Urbana: o caso do Conjunto Residencial José de Alencar. In: Cadernos de Geociências. Rio de Janeiro: IBGE, n.ํㅜ1, 1988. p. 47-62. 
MELLO, João Baptista Ferreira de. Geografia humanística: a perspectiva de experiência vivida e uma crítica radical ao positivismo. In: Revista Brasileira de Geografia. Rio de Janeiro: IBGE, 52, n.ํ 4, 1990. p. 91-115.

O Rio de Janeiro dos compositores da música popular brasileira (1928 - 1991): uma introdução à geografia humanística. Dissertação de Mestrado. Rio de Janeiro: UFRJ, 1991.

. Espaço, Lugar e "Deslugar". In: Redes. Rio de Janeiro, [s.n], v.1, n.ํㅡ, maio/ago. 1997.p. $93-109$.

Dos espaços da escuridão aos lugares de extrema luminosidade: o universo da estrela Marlene como palco e documento para a construção de conceitos geográficos. Tese de Doutorado. Rio de Janeiro: UERJ, 2000.

Valores em Geografia e o Dinamismo do Mundo Vivido na Obra de Anne Buttimer. In: Espaço e Cultura. Rio de Janeiro: EDUERJ, v. 1920, 2005. p. 33-39.

TUAN, Yi-Fu. Topofilia. São Paulo: Difel, 1980.

Espaço e Lugar. São Paulo: Difel, 1983.

Escapism. Baltimore: The Johns Hopkins University Press, 1998.

Paisagens do medo. São Paulo: Ed. UNESP, 2006.

\title{
Chords and melodies in the "broken city": the subject of the sociospace segregation sung by some carioca sambistas
}

\begin{abstract}
Discuss how the theme of spatial segregation in the city of Rio de Janeiro is experienced by some composers of the Mangueira Hill or supporters of this community, from the analysis of some letters of sambas is the main purpose of this communication. For this, we will use the theoretical and methodological chain called humanistic geography, especially the notions of space and place. Like other research produced within the current humanistic, this effort is sitting on subjectivity, intuition, feelings, experience, and the symbolism in the contingency, preferring the singular and not the particular or universal, and instead of the explanation has in understanding the basis for understanding the real world. The allusion to a world "mythical", "sacred", created over the years by the rich cultural production of the Mangueira Hill, besides the prestige of his college carnival, within the failings and negligence of the government, but in the compass of the kind of drum and the beating of their drums, forged an image laden with symbolism, which contributes to reducing stigma and biased representations of its residents, inserting them into the "formal city", dropping the "walls of the guard" between the slum and pavement, if not in the landscape urban, in the collective imagination.
\end{abstract}

Keywords: Humanistic Geography. Socio-spatial Segregation. Rio de Janeiro. Samba. Mangueira Slum.

\section{Acordes y melodías en la "ciudad rota”: el tema de la segregación del socioespacio cantado por algunos sambistas de carioca}

\footnotetext{
Resumen - Hable de cómo el tema de la segregación espacial en la ciudad de Río de Janeiro es experimentado por algunos compositores de la Manguera colina o los partidarios de esta comunidad, a partir del análisis de algunas letras de la trama sambas, es el principal objetivo de esta comunicación. Para ello, usaremos la cadena teórica y metodológica llamada geografía humanista, en especial las nociones de espacio y lugar. Al igual que otras investigaciones producidas dentro de la corriente humanista, este esfuerzo está sentado en la subjetividad, la intuición, los sentimientos, la experiencia y el simbolismo en la contingencia, prefiriendo el singular y no el particular o universal, y en lugar de la explicación se ha en la comprensión de la base para entender el mundo real. La alusión a un mundo "mítico", "sagrado", creado a lo largo de los años por la rica producción cultural de la Manguera colina, además del prestigio de su carnaval de la universidad, dentro de las fallas y negligencia del gobierno, pero en la brújula de los sordos y el batir de los tambores, forjaron una imagen cargada de simbolismo, que contribuye a reducir el estigma y la representación parcial de sus residentes, la inserción de ellos en la "ciudad formal", dejar caer los muros "de guardia" entre el barrio y el pavimento, si no en el paisaje urbano, en el imaginario colectivo.

Palabras clave: Geografía Humanista. Segregación Socio-espacial. Río de Janeiro. La Samba, La Manguera de Barrios Bajo.
} 